\title{
Progress on Synthesis of Low Content Inert Matrix Fuel Pellets
}

Nuclear Technology

Research and Development

\author{
Prepared for \\ U.S. Department of Energy \\ Advanced Fuels Campaign \\ R.L. Seibert and A.T. Nelson \\ Oak Ridge National Laboratory \\ September 13, 2019
}

Approved for public release.

Distribution is unlimited. 



\title{
DOCUMENT AVAILABILITY
}

Reports produced after January 1, 1996, are generally available free via US Department of Energy (DOE) SciTech Connect.

Website www.osti.gov

Reports produced before January 1, 1996, may be purchased by members of the public from the following source:

\author{
National Technical Information Service \\ 5285 Port Royal Road \\ Springfield, VA 22161 \\ Telephone 703-605-6000 (1-800-553-6847) \\ TDD 703-487-4639 \\ Fax 703-605-6900 \\ E-mail info@ntis.gov \\ Website http://classic.ntis.gov/
}

Reports are available to DOE employees, DOE contractors, Energy Technology Data Exchange representatives, and International Nuclear Information System representatives from the following source:

Office of Scientific and Technical Information

PO Box 62

Oak Ridge, TN 37831

Telephone 865-576-8401

Fax 865-576-5728

E-mail reports@osti.gov

Website http://www.osti.gov/contact.html

\begin{abstract}
This report was prepared as an account of work sponsored by an agency of the United States Government. Neither the United States Government nor any agency thereof, nor any of their employees, makes any warranty, express or implied, or assumes any legal liability or responsibility for the accuracy, completeness, or usefulness of any information, apparatus, product, or process disclosed, or represents that its use would not infringe privately owned rights. Reference herein to any specific commercial product, process, or service by trade name, trademark, manufacturer, or otherwise, does not necessarily constitute or imply its endorsement, recommendation, or favoring by the United States Government or any agency thereof. The views and opinions of authors expressed herein do not necessarily state or reflect those of the United States Government or any agency thereof.
\end{abstract}





\section{SUMMARY}

Progress was made on optimizing hot-press parameters for preparing fuel for two different coating methods: chemical vapor deposition (CVD) and chemical vapor infiltration (CVI). Surrogate materials, $\mathrm{CeO}_{2}$ and $\mathrm{ZrO}_{2}$, were used in place of $\mathrm{UO}_{2}$ and $\mathrm{PuO}_{2}$ for fuel development. Although the more porous $\mathrm{CeO}_{2}$ pellets were not successfully made to the extent that CVI would work with them as intended, hot-press parameters were optimized such that the pellets could be coated using CVD. The $\mathrm{ZrO}_{2} \mathrm{was}$ denser and therefore could more successfully be pressed to CVI standards; however, further improvement is needed before the process is implemented. Future work will continue to explore the optimization of a porous structure for CVI. 
This page is intentionally left blank. 


\section{CONTENTS}

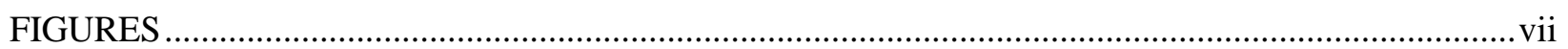

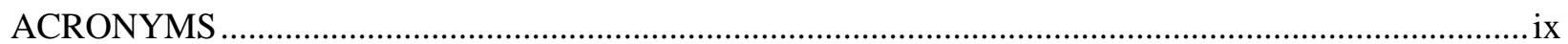

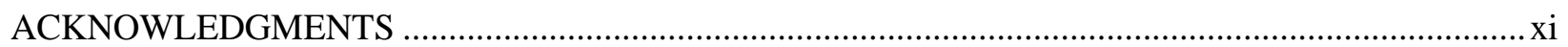

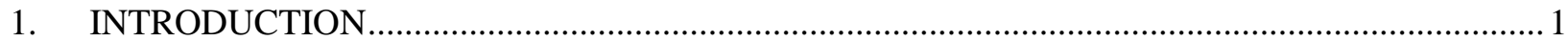

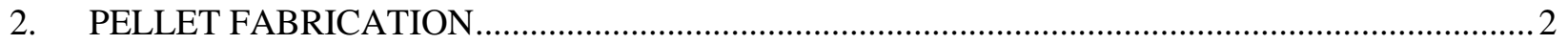

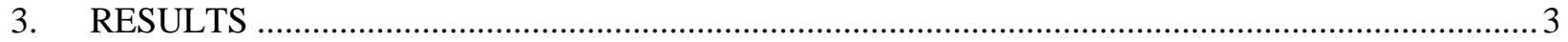

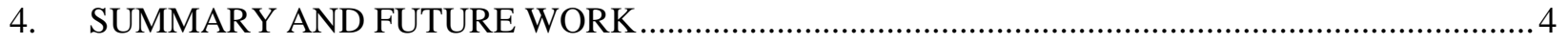

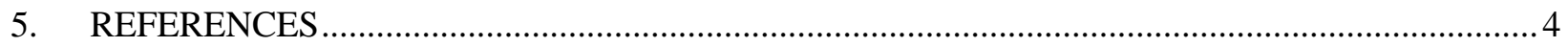


This page is intentionally left blank. 


\section{FIGURES}

Figure 1. Schematic illustration of the low volume content inert phase concept..................................... 1

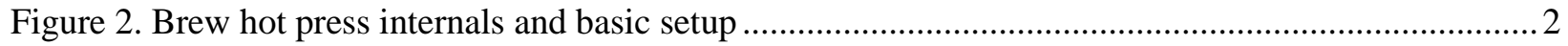

Figure 3. Scanning electron microscopy images of the $\mathrm{CeO}_{2}$ samples at the various target

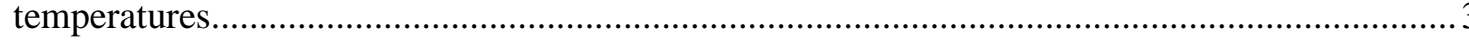

Figure 4. Scanning electron microscopy image of the $\mathrm{ZrO}_{2}$ sample showing a much more porous pellet, indicating potential for chemical vapor infiltration. 


\section{ACRONYMS}
AFC Advanced Fuels Campaign
CVD chemical vapor deposition
CVI chemical vapor infiltration
FCM fully ceramic microencapsulated 
This page is intentionally left blank. 


\section{ACKNOWLEDGMENTS}

The authors thank Rodney Hunt for fabrication of the $\mathrm{CeO}_{2}$ and James O. Kiggans Jr. for input on sintering. This work was supported by the Advanced Fuels Campaign of the US Department of Energy Office of Nuclear Energy. 
This page is intentionally left blank. 


\section{PROGRESS ON SYNTHESIS OF FUEL PELLETS FOR CHEMICAL VAPOR INFILTRATION}

\section{INTRODUCTION}

This is a progress report on efforts to prepare low volume content inert matrix fuels. There is interest in using drop-in fuels for the existing reactor fleet without increasing current uranium enrichment but maintaining or improving reactor fuel performance. It has been proposed that we can use fuel with only a limited volume or inert phases by pressing pellets of fuel (with little to no sintering aid) and infiltrating the pellets using chemical vapor infiltration (CVI) to create a protective barrier, to increase structural integrity of the fuel, and to provide a seal on the pressed pellet.

The concept is illustrated conceptually in Figure 1. High density particle fuels such as UC or UN would be produced using established methods. Kernels of both UC and UN have been fabricated during the US Department of Energy Office of Nuclear Energy Advanced Fuels Campaign (AFC) and Advanced Gas Reactor program (for example, see McMurray et al. [1]). Kernels would be consolidated using pressureless sintering, hot pressing, or an as yet undetermined process to generate a partially densified pellet. The goal of the process is to retain significant open porosity. This pellet would then be subsequently infiltrated using processes developed previously by AFC researchers [2]. Silicon carbide is the most mature material that has been used in this process and would represent a strong initial candidate given that it is reasonably compatible with water coolants at reactor operating temperatures and is generally chemically inert. It would therefore be a reasonable means to waterproof a high-density fuel such as UC or UN. Given the nature of the CVI process, it is likely that an inner region free of SiC (shown at radius $R_{V}$ in Figure 1) and an outer (skin) region free of fuel (thickness $R-R_{F}$ in Figure 1) would also be generated.

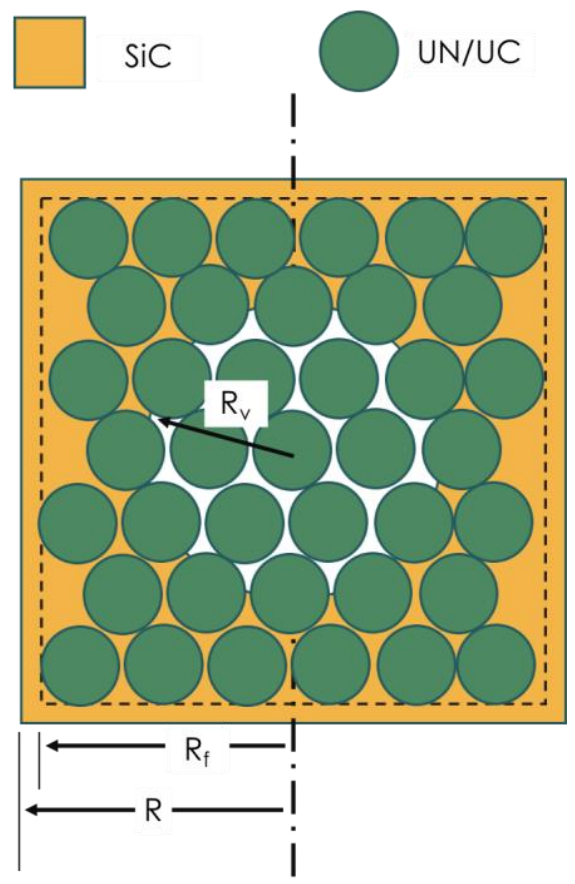

Figure 1. Schematic illustration of the low volume content inert phase concept. Here high-density fuel particles (UN or UC) are consolidated in a manner to maintain open porosity. A chemical vapor infiltration process is then used to encase the pellet in a robust, chemically inert matrix such as $\mathrm{SiC}$. 
The fuel concept illustrated in Figure 1 is at the exploratory stage. Key challenges to implementation include (a) obtaining high quality microstructures; (b) verifying thermomechanical performance of the system (i.e., ensuring differences in thermal expansion or residual stresses do not induce pulverization during temperature ramps); (c) establishing that $\mathrm{SiC}$ or another matrix material can protect the vulnerable UC or UN; and finally, but most importantly, (d) verifying the irradiation performance. The initial steps necessary to evaluate this concept are fabrication of representative microstructures and verification of both homogeneity and thermomechanical stability. In this study, the first step in fabrication has been pursued using surrogate materials. We discuss two forms of surrogates, porous $\left(\mathrm{CeO}_{2}\right)$ and dense $\left(\mathrm{ZrO}_{2}\right)$, and results of hot pressing each. The goal of this work is to establish possible initial microstructures, the open porosity attainable using these materials, and optimal processing conditions. If successful, the next stages will include demonstration and optimization of $\mathrm{SiC}$ deposition using the CVI process and eventual translation to uranium fuels.

\section{PELLET FABRICATION}

Surrogate $\mathrm{UO}_{2}$ pellets were fabricated using either $500 \mu \mathrm{m} \mathrm{CeO}_{2}$ feedstock produced by Oak Ridge National Laboratory (ORNL) or $200 \mu \mathrm{m} \mathrm{ZrO}$ from Tosoh (The $\mathrm{ZrO}_{2}$ is yttria-stabilized zirconia, which is $\mathrm{ZrO}_{2}$ stabilized by $5 \% \mathrm{Y}_{2} \mathrm{O}_{3}$ ). Only one size of each fuel type was used with the intent of leaving space both for CVI to fill and for fuel expansion during operation, as maximized particle packing was not desired. The $\mathrm{CeO}_{2}$ was of medium porosity and was created by ORNL as described elsewhere $[3,4]$. About $0.7 \mathrm{~g}$ of each material type was used to create a disk $9.8 \mathrm{~mm}$ in diameter by about $1.5 \mathrm{~mm}$ in height.

A brew hot press, shown in Figure 2, was used for sintering the surrogate fuel. Particles were pressed in a $9.8 \mathrm{~mm}$ graphite die with graphite foil (grafoil) protecting both ends of the powder. Runs were conducted at $1,000^{\circ} \mathrm{C}, 1,200^{\circ} \mathrm{C}$, and $1,400^{\circ} \mathrm{C}$ for the $\mathrm{CeO}_{2}$, and a single run at $1,550^{\circ} \mathrm{C}$ was conducted for the $\mathrm{ZrO} 2$. The $\mathrm{ZrO}_{2}$ was run at a higher temperature as previous experiments had indicated better sintering at higher temperatures (up to $1,600^{\circ} \mathrm{C}$, at which point the grafoil within the press reacts with the $\mathrm{ZrO}_{2}$ ). All runs were conducted at $25 \mathrm{MPa}$. A ramping rate of $15^{\circ} \mathrm{C} / \mathrm{min}$. was used to bring the furnace up to temperature in all cases.

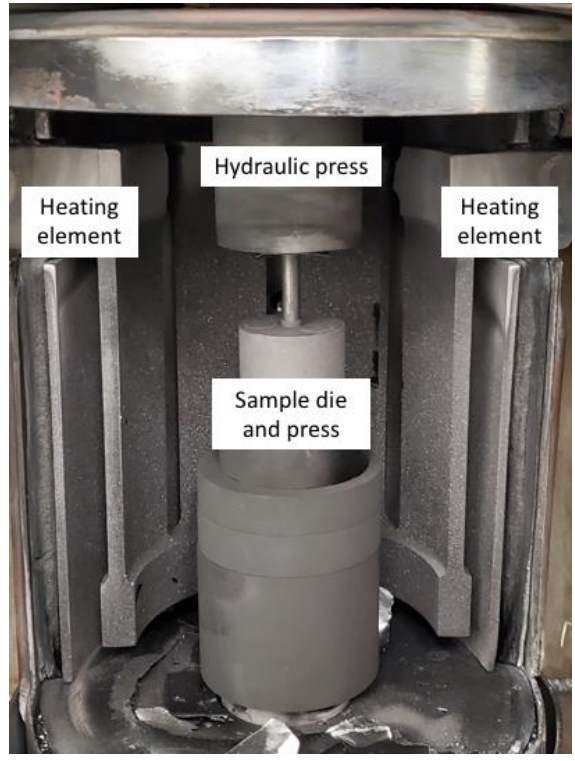

Figure 2. Brew hot press internals and basic setup. 


\section{RESULTS}

The $\mathrm{CeO}_{2}$ densified regardless of temperature at the chosen pressure. This is likely due to the initially porous nature of the material. In Figure 3, an example from all three target temperatures is shown. At all temperatures, the particle did not have a porous structure as originally expected. At $1,000^{\circ} \mathrm{C}$, the particle was fragile enough to break with handling and had small-scale cracking [Figure $3(\mathrm{~d})$ ]. At $1,200^{\circ} \mathrm{C}$, the particle was stable but densified such that only chemical vapor deposition (CVD) coating would be appropriate for the particle. And at $1,400^{\circ} \mathrm{C}$, the $\mathrm{CeO}_{2}$ started to react with the grafoil, leading to degradation and transformation of the material as shown in Figure 3(f). This porous surrogate material was clearly not appropriate for preparing for CVI but did produce particles at $1,200^{\circ} \mathrm{C}$ that would be candidates for CVD coating for other reactor applications.

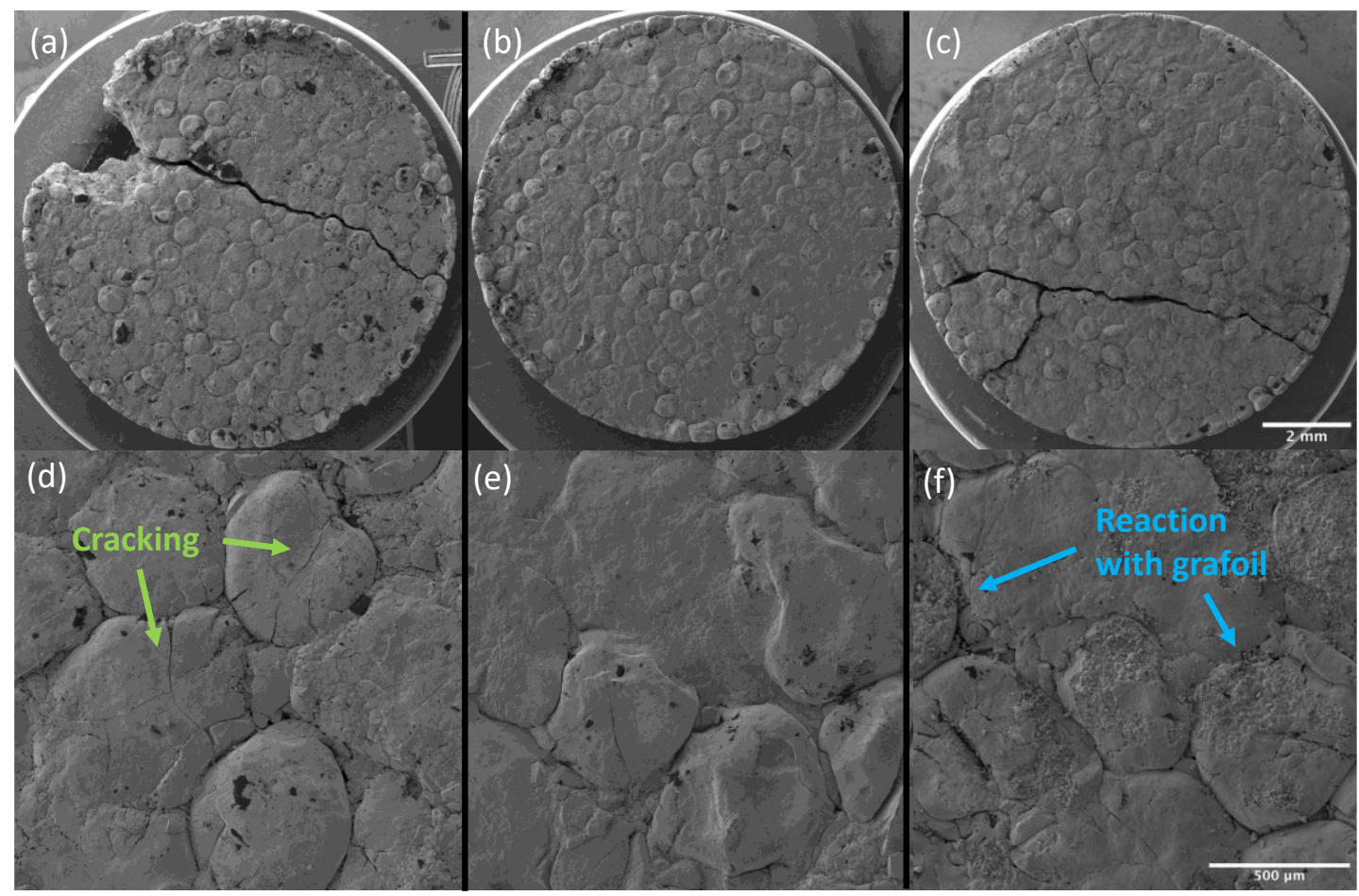

Figure 3. Scanning electron microscopy images of the $\mathrm{CeO}_{2}$ samples at the various target temperatures: $1,000^{\circ} \mathrm{C}\left[(\mathrm{a})\right.$ and (d)], which showed cracking; $1,200^{\circ} \mathrm{C}\left[(\mathrm{b})\right.$ and (e)]; and $1,400^{\circ} \mathrm{C}[(\mathrm{c})$ and (f)], which showed reaction to the grafoil.

The $\mathrm{ZrO}_{2}$ surrogate material was denser and therefore was used to determine whether denser material would pack in such a manner that CVI would be feasible. Although the material did pack with more porosity, as shown in Figure 4, the conditions were not optimal for CVI infiltration. The particles began to fuse together, leaving no space for infiltration to penetrate much farther than the first few layers. For the $\mathrm{ZrO}_{2}$ to be a candidate for CVI, it would need to be sintered under less pressure or at a lower temperature so that the porosity to increased. This is being studied for future fuel preparation. 


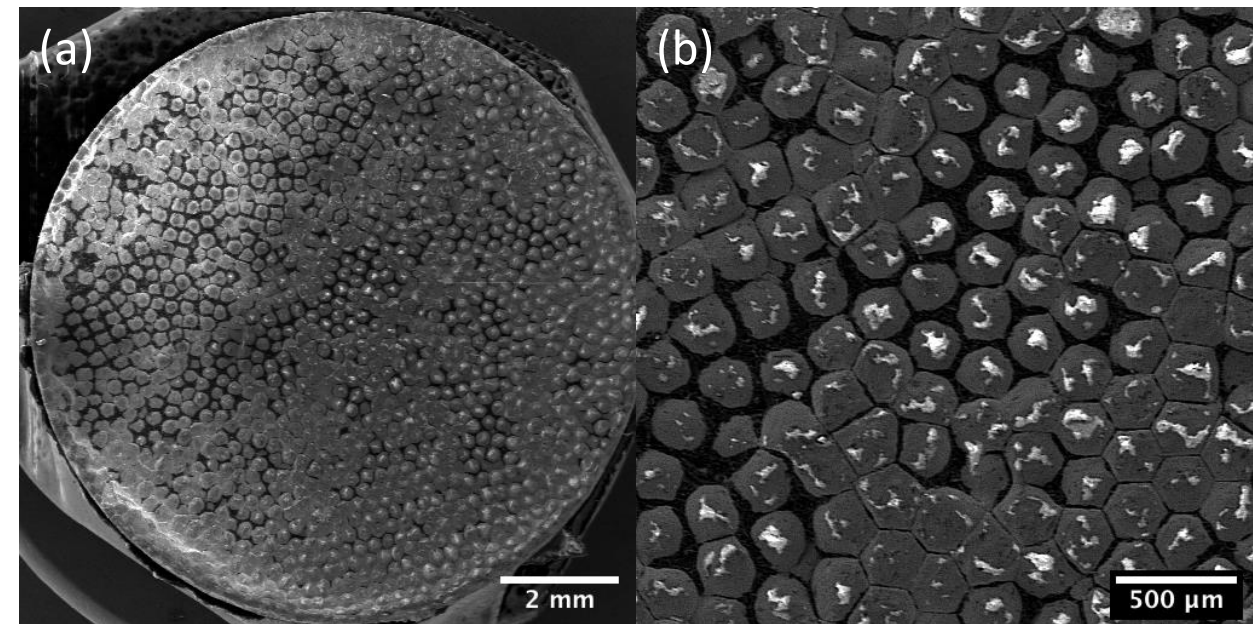

Figure 4. (a) Scanning electron microscopy image of the $\mathrm{ZrO}_{2}$ sample and (b) a magnified image showing a much more porous pellet, indicating potential for chemical vapor infiltration.

\section{SUMMARY AND FUTURE WORK}

We have shown that hot pressing porous $\mathrm{CeO}_{2}$ feedstock does not result in ideal pellets for infiltration but rather makes denser pellets only useful for CVD coating. CVD would not infiltrate the pellet matrix but rather be a singular coating outside the pellet, acting like a protective shell. Dense $\mathrm{ZrO}_{2}$ spheres are more promising for CVI, but optimization of pressing parameters is still necessary. Future work will include optimizing the hot-press parameters by adjusting pressure and temperature and coating these pellets using CVI to produce a high performing inert matrix fuel.

\section{REFERENCES}

[1] J. McMurray, J. Kiggans, G. Helmreich, and K. Terrani "Production of near-full density uranium nitride microspheres with a hot isostatic press," J. Am. Ceram. Soc. 101, 4492-4497 (2018).

[2] K. Terrani, M. Trammell, B. Jolly, R. Seibert, F. Montgomery, and H. Wang Application of Binderjet Technology for Advanced Manufacturing of Ceramic Components, ORNL/SPR-2018/949, August 2018.

[3] R.D. Hunt, J.L. Collins, T.J. Reif, B.S. Cowell, and J.A. Johnson, "Key process parameters to modify the porosity of cerium dioxide microspheres formed in the internal gelation process," J. Nucl. Mater. 495, 33-37 (2017).

[4] R.D. Hunt, J.L. Collins, and B.S. Cowell, "Use of boiled hexamethylenetetramine and urea to increase the porosity of cerium dioxide microspheres formed in the internal gelation process," J. Nucl. Mater. 492, $1-5$ (2017). 